Article

\title{
Effect of Nickel Oxide Doping to Ceria-Supported Gold Catalyst for CO Oxidation and Water-Gas Shift Reactions
}

\author{
Miao Shu ${ }^{1,4}$, Shuai Wei ${ }^{2}$, Chun-Jiang Jia ${ }^{2}$, Dao-Lei Wang ${ }^{3}$ and Rui Si ${ }^{1, *}$ \\ 1 Shanghai Synchrotron Radiation Facility, Shanghai Institute of Applied Physics, Chinese Academy of \\ Sciences, Shanghai 201204, China; shumiao@sinap.ac.cn \\ 2 Key Laboratory for Colloid and Interface Chemistry, Key Laboratory of Special Aggregated Materials, \\ School of Chemistry and Chemical Engineering, Shandong University, Jinan 250100, China; \\ weishuai@mail.sdu.edu.cn (S.W.); jiacj@sdu.edu.cn (C.-J.J.) \\ 3 Division of China, TILON Group Technology Limited, Shanghai 200090, China; gavin.wang@tilon.com.cn \\ 4 University of Chinese Academy of Science, Beijing 100049, China \\ * Correspondence: sirui@sinap.ac.cn; Tel.: +86-3393-2079
}

Received: 31 August 2018; Accepted: 27 September 2018; Published: 26 November 2018

\begin{abstract}
Ceria-supported gold catalyst has drew much research interest owing to its high reactivity on CO oxidation and water-gas shift (WGS) reactions. However, till now, there were relatively limited studies on the effect of secondary metal/metal oxide component into gold-ceria system to enhance its catalytic performance. In this work, we synthetized the ceria supported gold-nickel samples via a deposition-precipitation method with the base of $\mathrm{NaHCO}_{3}$ to adjust final $\mathrm{pH}$ value of $8 \sim 9$. We found that the addition of nickel oxide drove off the gold species from the stock solution during synthesis, and thus resulted in a dramatical decrease on doped Au concentration. No crystallized phases of gold and nickel were observed on the surface of ceria nanorods in both X-ray diffraction (XRD) and transmission electron microscopy (TEM). The valence of nickel was maintained as $\mathrm{Ni}^{2+}$ for all the measured samples by X-ray photoelectron spectroscopy (XPS), while gold was oxidized with the increased nickel amount after analysis of $X$-ray absorption near edge spectroscopy (XANES). The corresponding catalytic tests showed that with the introduction of nickel oxide, the activity of gold-ceria catalyst was promoted for the WGS reaction, but inhibited for the CO oxidation reaction.
\end{abstract}

Keywords: gold; ceria; nickel oxide; CO oxidation; water-gas shift

\section{Introduction}

There are considerable research have ascertained that supported metal catalysts, especially to gold catalysts, are extraordinarily active for oxidation of carbon monoxide $\left(2 \mathrm{CO}+\mathrm{O}_{2}=2 \mathrm{CO}_{2}\right)[1-6]$ and water-gas shift $\left(\mathrm{CO}+\mathrm{H}_{2} \mathrm{O}=\mathrm{CO}_{2}+\mathrm{H}_{2}\right)$ [7-12] reaction. Up to present, a great deal of research work has focused on the "structure-activity" relationship in supported gold catalyst, such as the type of oxide support [1,7,13-17], the gold size effect [17-20], the oxidation state of gold [21] and the metal-support interaction [5,17]. For instance, Carrettin et al. reported that nanocrystalline $\mathrm{CeO}_{2}$ supported gold nanoparticles are more active than those anchored on other oxides $\left(\mathrm{TiO}_{2}, \mathrm{Fe}_{2} \mathrm{O}_{3}\right)$ for $\mathrm{CO}$ oxidation [1]. $\mathrm{Si}$ et al. synthetized $\mathrm{CeO}_{2}$ to produce three shapes (nanorod, nanocube, nanopolyhedron) as the support, and the light-off profiles of WGS reaction elucidated that rod-like $\mathrm{CeO}_{2}$ expose more $\{110\}$ and $\{100\}$ planes which are most active for gold stabilization and activation [7]. Fu et al. confirmed that gold nanoparticles are essential for some oxidation reactions, but unimportant in WGS reaction over Au-ceria [22]. On the basis of these findings, we can see the significant importance of physical and chemical properties of Au modified by the matrix. 
Although single metal gold catalyst has been studied profoundly during the last two decades, the research on the bimetallic gold catalyst was still limited [23-25], especially for the effect of low-price transition metal or metal oxide doping $[24,26,27]$. Few practical preparation routes have been achieved in the fine control on the formation of bimetallic catalyst at the subnanometer scale [26,27]. For example, Scott et al. reported the synthesis and characterization of $\mathrm{TiO}_{2}$-supported Pd-Au bimetallic nanoparticle catalysts prepared using dendrimer-encapsulated nanoparticles [23] and Eveline et al. prepared Pt-Au bimetallic cluster supported on the $\mathrm{SiO}_{2}$ or $\mathrm{TiO}_{2}$ by wet impregnation to investigated the electronic structure of platinum and gold differed from that in the monometallic clusters [25]. However, the size of bimetallic cluster or nanoparticle were larger than $2 \mathrm{~nm}$ in the above work. On the other hand, it is extremely difficult to precisely explore the electronic structure and geometric structure of low-concentration active metals. In recent years, combination between aberration-corrected transmission electronic microscopy (TEM) and X-ray adsorption fine structure (XAFS) techniques provide a comprehensive characteristic approach to identify the structural information on small-size bimetallic species anchored on the surface of oxide matrix [11,28-30]. Previously, Qiao et al. took the lead in proposing the single atom catalyst that $\mathrm{FeO}_{\mathrm{x}}$ supported $\mathrm{Pt}$ single-atom and characterized by aberration-corrected high-angle annular dark-field scanning transmission electron microscopy (HAADF-STEM) and XAFS, revealed that Pt isolated single atoms structure [28], Guo et al. compared different Au species (atom, cluster, particle) and confirmed the metal gold is the active species during CO oxidation with the help of HAADF-STEM and XAFS techniques [21]. These investigations confirmed the possibility of obtaining reliable and accurate structural information around gold active species.

Owing to the easily reversible transformation between $\mathrm{Ce}^{3+}$ and $\mathrm{Ce}^{4+}$, nanosized cerium oxide $\left(\mathrm{CeO}_{2}\right)$ always applied to the reducible oxide support to deposit different metals or oxide [1,22]. For example, our group prepared conformably dispersed subnanometer copper [31] and iron [32] oxide clusters on $\mathrm{CeO}_{2}$. Our previous findings also indicated that ceria-supported gold catalyst is very active for both CO oxidation [21] and WGS [7] reactions. In addition, some research groups found the synergetic effect of gold and nickel $[33,34]$. For example, Shirakawa et al. reported the gold atoms improve the release of oxygen from nickel atoms of $\mathrm{NiO}$ within cluster [33]. Thus, in this work, we tried to combine the effect of nickel on gold activity and the structure-activity relationship on WGS and CO oxidation reactions. Herein, in this work, we report the synthesis of nanorod-like ceria-supported gold-nickel catalyst via a deposition-precipitation method with bicarbonate sodium as precipitating agent, as well as the multiple characterizations such as X-ray diffraction (XRD), X-ray photoelectron spectroscopy (XPS), TEM and XAFS towards the comprehensive structural properties of these nickel-doped gold-ceria samples. Furthermore, we elucidate the effect of nickel oxide in catalysis by catalytic tests for both CO oxidation and WGS reactions, in which the introduction of nickel displays totally different performance (positive/negative effect) on the above reactions.

\section{Results}

\subsection{Effect of Nickel Oxide during Deposition of Gold}

In this work, the concentration of gold or nickel was designed to be fixed at 1 or 5 at $\%$, respectively. During the catalyst preparation, we investigated three different precipitating agents: ammonium carbonate $\left(\left(\mathrm{NH}_{4}\right)_{2} \mathrm{CO}_{3}\right)$, sodium carbonate $\left(\mathrm{Na}_{2} \mathrm{CO}_{3}\right)$ and sodium hydrogen carbonate $\left(\mathrm{NaHCO}_{3}\right)$, and found that: (1) $\left(\mathrm{NH}_{4}\right)_{2} \mathrm{CO}_{3}$ is very suitable for gold deposition onto pure ceria [7], but nickel ion was complexed with molecular ammonia, which is prejudicial to the deposition of nickel; (2) When $\mathrm{Na}_{2} \mathrm{CO}_{3}$ is added, the fast growth of nickel phase made the $\mathrm{NiO}$ crystallized easily; (3) If $\mathrm{NaHCO}_{3}$ is used as precipitant, no large-size gold or nickel phase appeared. Therefore, we finally selected sodium hydrogen carbonate as the base to simultaneously precipitate both gold and nickel ions.

Table 1 shows that the experimental loading of gold concentrations ( $\mathrm{Au}$ ), determined by inductively coupled plasma atomic emission spectroscopy (ICP-AES), are 0.21 and 0.13 at $\%$ for 
ceria-supported pure gold (AuCe) and gold-nickel (AuNiCe) samples, respectively. Clearly, there was ca. $40 \%$ loss of gold species during the applied deposition-precipitation process. Here, we hypothesized that the as-formed $\mathrm{Ni}(\mathrm{OH})_{x}\left(\mathrm{H}_{2} \mathrm{O}\right)_{y}$ nucleation in stock solution can cover part of ceria surface and drive the $\mathrm{Au}(\mathrm{OH})_{x}\left(\mathrm{H}_{2} \mathrm{O}\right)_{y}$ nuclei off from the oxide support. Since the purpose of this work is focused on the formation of small-size gold and nickel atoms or clusters, we accepted this gold loss, which could be compensated by the normalization of catalytic reactivity.

Table 1. Au and Ni bulk concentration, atomic ratios $(\mathrm{Ni} /(\mathrm{Ni}+\mathrm{Ce}))$ on the surface, BET Specific surface areas $\left(S_{\mathrm{BET}}\right), \mathrm{BJH}$ (Barett-Joyner-Halenda) pore volume $\left(V_{\mathrm{p}}\right)$, lattice constants $(a)$ of $\mathrm{CeO}_{2}$, averaged grain sizes $(D)$ for $\mathrm{AuNi} / \mathrm{CeO}_{2}$ samples.

\begin{tabular}{|c|c|c|c|c|c|c|c|}
\hline Sample & $\mathrm{Au}(\mathrm{at} \%)^{a}$ & $\mathrm{Ni}(\mathrm{at} \%)^{a}$ & $\begin{array}{c}S_{\mathrm{BET}} \\
\left(\mathrm{m}^{2} / \mathrm{g}\right)\end{array}$ & $\begin{array}{c}V_{\mathrm{p}} \\
\left(\mathrm{cm}^{3} / \mathrm{g}\right)^{c}\end{array}$ & $a(\AA)^{d}$ & $\begin{array}{l}D_{\mathrm{XRD}} \\
(\mathrm{nm})^{d}\end{array}$ & $\begin{array}{c}D_{\text {TEM }} \\
(\mathbf{n m}) g\end{array}$ \\
\hline $\mathrm{AuCe}$ & $0.21(0.04)$ & - & 99 & 0.44 & $\begin{array}{c}5.4134(2) \\
5.4157(3)^{e} \\
5.4100(1)^{f}\end{array}$ & 9.4 & $\begin{array}{c}8.1(1.8)^{h} \\
20-150^{i}\end{array}$ \\
\hline AuNiCe & $0.13(0.05)$ & $\begin{array}{c}3.9(0.1) \\
4.5,3.8,4.3 \\
b\end{array}$ & 99 & 0.53 & $\begin{array}{c}5.4088(1) \\
5.4108(1)^{e} \\
5.4149(1)^{f}\end{array}$ & 9.7 & $\begin{array}{c}8.7(1.9)^{h} \\
20-150^{i}\end{array}$ \\
\hline
\end{tabular}

\footnotetext{
${ }^{a}$ Determined by ICP-AES; ${ }^{b}$ Determined by XPS for fresh, used after CO oxidation and used after WGS, respectively;

${ }^{c}$ From $\mathrm{N}_{2}$ adsorption / desorption; ${ }^{d}$ From XRD; ${ }^{e}$ After CO oxidation reaction; ${ }^{f}$ After WGS reaction; ${ }^{g}$ From TEM; ${ }^{\prime}$

Width; ${ }^{i}$ Length. Numbers in brackets are errors.
}

\subsection{Structural and Textural Properties for Ceria-Supported Gold-Nickel Catalysts}

The nitrogen adsorption/desorption experiment was used to investigate the textural properties for fresh samples. Table 1 shows that BET specific surface areas of AuCe and AuNiCe identical $\left(99 \mathrm{~m}^{2} / \mathrm{g}\right)$. The related adsorption/desorption isotherms and pore diameter distribution histograms are shown in Figure 1a,b, respectively. All the adsorption/desorption curves are defined as the type IV isotherm. The hysteresis loop appear in the $P / P^{0}$ range of $0.8-1.0$ associated with AuCe or AuNiCe is type $\mathrm{H} 3$, which identifies the materials consisted of aggregated particles [35]. Figure $1 \mathrm{~b}$ shows that AuNiCe appears slightly larger average pore diameter $(20.5 \mathrm{~nm}) / \mathrm{BJH}$ pore volumes $\left(0.53 \mathrm{~cm}^{3} / \mathrm{g}\right)$ than those for AuCe $\left(18.3 \mathrm{~nm}, 0.44 \mathrm{~cm}^{3} / \mathrm{g}\right)$, indicating the addition of nickel may add extra surface layers of ceria nanorods. Nevertheless, all the above data demonstrate that the introduction of Ni actually did not bring major changes for the textural properties of our ceria-supported gold catalyst.

(a)

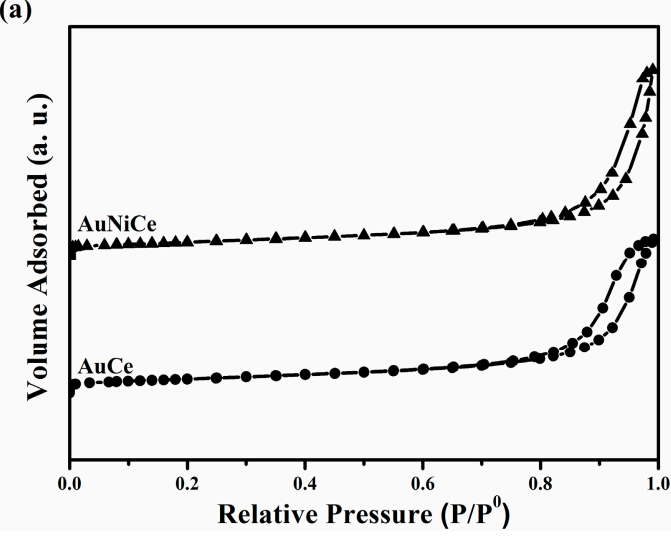

(b)

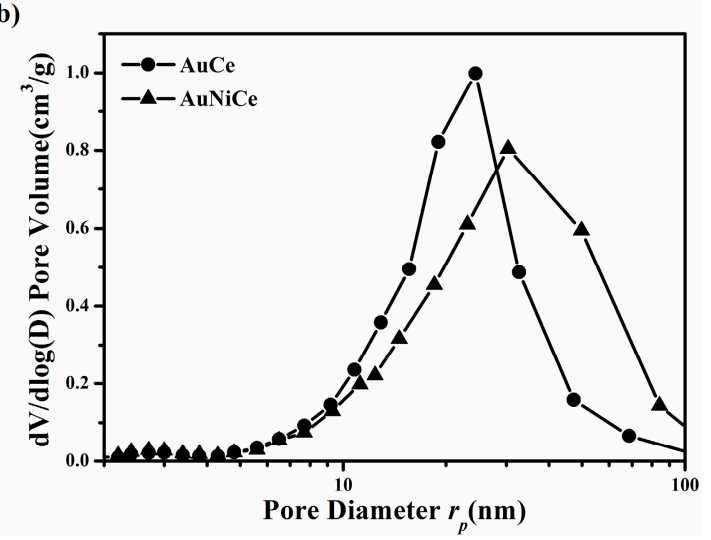

Figure 1. $\mathrm{N}_{2}$ adsorption measurements of fresh $\mathrm{AuNi} / \mathrm{CeO}_{2}$ samples: (a) adsorption-desorption isotherm; (b) BJH pore size distribution.

TEM and high resolution transmission microscopy (HRTEM) were used to verify the morphology of ceria supported gold-nickel samples. As shown in Figure 2, $\mathrm{CeO}_{2}$ support is composed by nanorods 
with 20-150 nm length and uniform diameter, and their average widths $(8.1-8.7 \mathrm{~nm})$ are nearly the same between AuCe and AuNiCe (see Table 1). Figure 3a,c confirm the $f c c$ structure for $\mathrm{CeO}_{2}$ in both of the investigated samples, and no lattice fringes of $\mathrm{Au}$ or $\mathrm{Ni} / \mathrm{NiO}$ were detected. Figure $3 \mathrm{~b}, \mathrm{~d}$ verify the homogenous dispersions of either $\mathrm{Au}$ or $\mathrm{Ni}$ on the surface of $\mathrm{CeO}_{2}$ for both pure and Ni-doped $\mathrm{Au} / \mathrm{CeO}_{2}$ catalysts at the nanometer scale by the aids of scan transmission electron microscopy-energy dispersive spectrometer (STEM-EDS) mappings. Thus, on the basis of microdomain characterizations, we can draw a conclusion that the introduced gold and nickel ions were uniformly converted to deposited species on the surface of $\mathrm{CeO}_{2}$ nanorods during our synthesis.

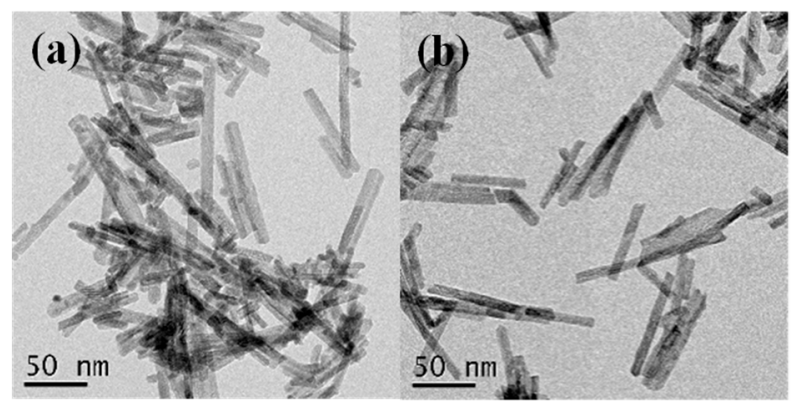

Figure 2. TEM images of fresh $\mathrm{AuNi} / \mathrm{CeO}_{2}$ samples: (a) AuCe; (b) AuNiCe.
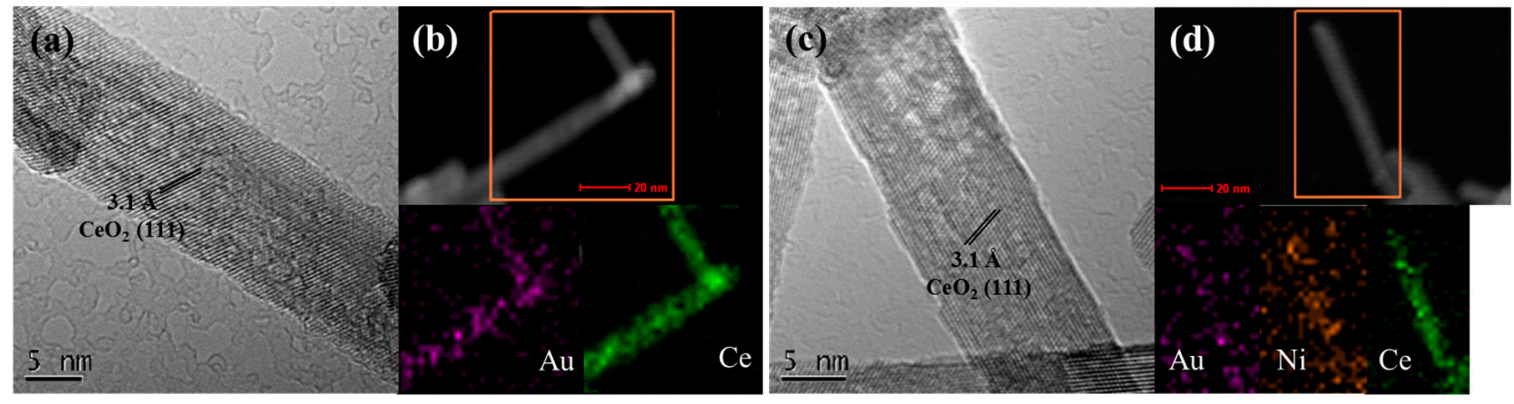

Figure 3. HRTEM images $(\mathbf{a}, \mathbf{c})$ and STEM-EDS mapping results $(\mathbf{b}, \mathbf{d})$ of fresh $\mathrm{AuNi} / \mathrm{CeO}_{2}$ samples: (a,b) AuCe; (c,d) AuNiCe.

\subsection{Catalytic Performance of Ceria-Supported Gold-Nickel Catalysts}

The catalytic performance of the as-synthetized ceria supported gold-nickel samples was evaluated by both CO oxidation and WGS reactions. Figure $4 \mathrm{a}, \mathrm{b}$ display the limited activity of gold-free samples (NiCe) for these two reaction, confirming the importance of Au to activate the $\mathrm{CO}$ conversion. Figure $4 \mathrm{a}$ shows that the introduction of nickel impaired the reactivity of gold-ceria catalyst. Correspondently, Table 2 lists that the temperature of $50 \%$ conversion $\left(T_{50}\right)$ for CO oxidation is raised from $50{ }^{\circ} \mathrm{C}(\mathrm{AuCe})$ to $66^{\circ} \mathrm{C}(\mathrm{AuNiCe})$, and the reaction rate normalized by gold amount at $40{ }^{\circ} \mathrm{C}$ decreases from 1030 (AuCe) to $631 \mu \mathrm{mol} \mathrm{g} \mathrm{Au}^{-1} \mathrm{~s}^{-1}$ (AuNiCe). The higher reaction rate obtained over gold-ceria samples is comparable to that of Au supported on ceria nanorods synthesized by deposition-precipitation with $\mathrm{NaOH}$ as precipitating agent under the same reaction conditions $\left(1167 \mu \mathrm{mol} \mathrm{g}_{\mathrm{Au}}{ }^{-1} \mathrm{~s}^{-1}\right)$ [15]. On the other hand, Figure $4 \mathrm{~b}$ shows the activity in WGS reaction as a function of reaction temperature. Clearly, the addition of nickel significantly promoted the reactivity of gold-ceria catalyst. It is important to highlight that the reaction rate normalized by gold concentration at $250{ }^{\circ} \mathrm{C}$ increases from AuCe $\left(781 \mu \mathrm{mol} \mathrm{g}_{\mathrm{Au}}{ }^{-1} \mathrm{~s}^{-1}\right)$ to AuNiCe $\left(2542 \mu \mathrm{mol} \mathrm{g}_{\mathrm{Au}}{ }^{-1} \mathrm{~s}^{-1}\right.$, see Table 2). Therefore, we can draw a conclusion that the nickel doping indeed has positive effect for the WGS reaction, while negative effect for the $\mathrm{CO}$ oxidation reaction in this work. 
Table 2. $\mathrm{H}_{2}$ reduction temperatures $\left(T_{\mathrm{R}}\right) ; \mathrm{H}_{2}$ theoretical and real consumption values; temperatures of $50 \%$ conversion $\left(T_{50}\right)$ and reaction rates $(r)$ of $\mathrm{CO}$ oxidation and WGS reactions for $\mathrm{AuNi} / \mathrm{CeO}_{2}$ samples.

\begin{tabular}{cccccc}
\hline Sample & $\boldsymbol{T}_{\mathbf{R}}\left({ }^{\circ} \mathbf{C}\right)^{a}$ & $\begin{array}{c}\mathbf{H}_{\mathbf{2}} \text { Consump. } \\
\left(\mu \mathrm{mol} / \mathrm{g}_{\mathrm{cat}}\right)\end{array}$ & $\begin{array}{c}\mathbf{T}_{\mathbf{5 0}}\left({ }^{\circ} \mathrm{C}\right) \mathrm{CO} \\
\text { Oxidation }\end{array}$ & $\begin{array}{c}\mathbf{C O ~ O x i d a t i o n ~}^{c} \\
\left(\mathbf{4 0}{ }^{\circ} \mathbf{C}\right)\end{array}$ & $\begin{array}{c}\mathbf{W G S}^{d} \\
\left(\mathbf{2 5 0}{ }^{\circ} \mathbf{C}\right)\end{array}$ \\
\hline AuCe & 118 & $341^{a}(5)^{b}$ & 50 & 1030 & 781 \\
AuNiCe & 146 & $1278(525)$ & 66 & 631 & 2542 \\
\hline
\end{tabular}

${ }^{a}$ Calculate from $\mathrm{H}_{2}$-TPR $\left(5 \% \mathrm{H}_{2} / \mathrm{Ar}, 30 \mathrm{~mL} / \mathrm{min}\right) ;{ }^{b}$ Calculate from $\mathrm{Au}^{\delta+} \rightarrow \mathrm{Au}^{0}$ and $\mathrm{Ni}^{2+} \rightarrow \mathrm{Ni}^{0} ;{ }^{c} \mathrm{Test}$ in CO oxidation reaction $\left(1 \% \mathrm{CO} / 20 \% \mathrm{O}_{2} / 79 \% \mathrm{~N}_{2}\right)$; ${ }^{d}$ Test in WGS reaction $\left(2 \% \mathrm{CO} / 10 \% \mathrm{H}_{2} \mathrm{O} / 88 \% \mathrm{~N}_{2}\right)$. Consump.: Consumption.

(a)

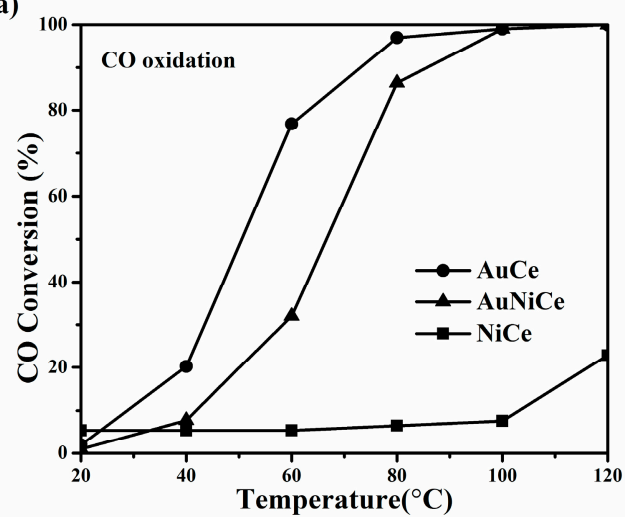

(b)

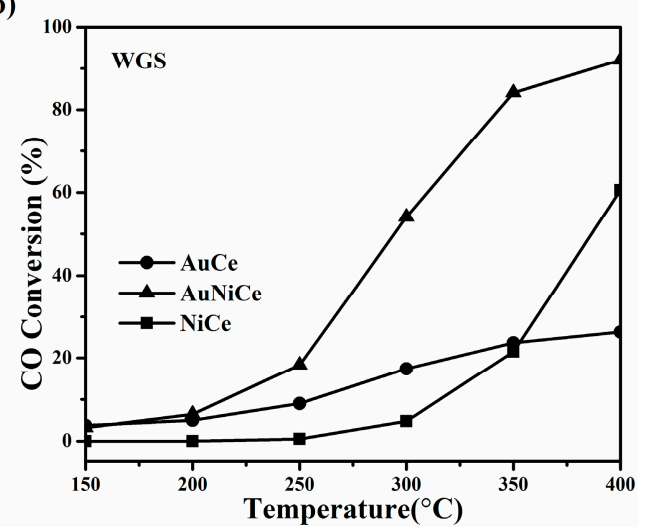

Figure 4. "Light off" profiles of $\mathrm{AuNi} / \mathrm{CeO}_{2}$ samples for: (a) $\mathrm{CO}$ oxidation reaction $\left(1 \% \mathrm{CO} / 20 \% \mathrm{O}_{2} / 79 \%\right.$ $\left.\mathrm{N}_{2}, 80,000 \mathrm{~mL} \mathrm{~g}_{\text {cat }}{ }^{-1} \mathrm{~h}^{-1}\right)$; (b) WGS reaction $\left(2 \% \mathrm{CO} / 10 \% \mathrm{H}_{2} \mathrm{O} / 88 \% \mathrm{~N}_{2}, 84,000 \mathrm{~mL} \mathrm{~g}_{\text {cat }}{ }^{-1} \mathrm{~h}^{-1}\right)$.

\subsection{Structural and Textural Properties for Used Ceria-Supported Gold-Nickel Catalysts}

To better understand the origin of doping effect by nickel over the studied gold-ceria catalyst, we further investigated the related samples by the aids of more characterization techniques. Figure 5 shows that fresh AuCe and AuNiCe are of $f c c \mathrm{CeO}_{2}$ phase (JCPDS card no.: 34-394) with lattice constants $a$ around $5.41 \AA$ and the average grain size of 9.4-9.7 nm (see Table 1). Beyond that, there is no other component including $\mathrm{Au}$ or $\mathrm{Ni} / \mathrm{NiO}$ can be identified in the patterns, which is in good agreement with the TEM results. It is probably due to the low loading of $\mathrm{Au}$ and/or small-size atoms or clusters of deposited Au or Ni species over the ceria surface.

(a)

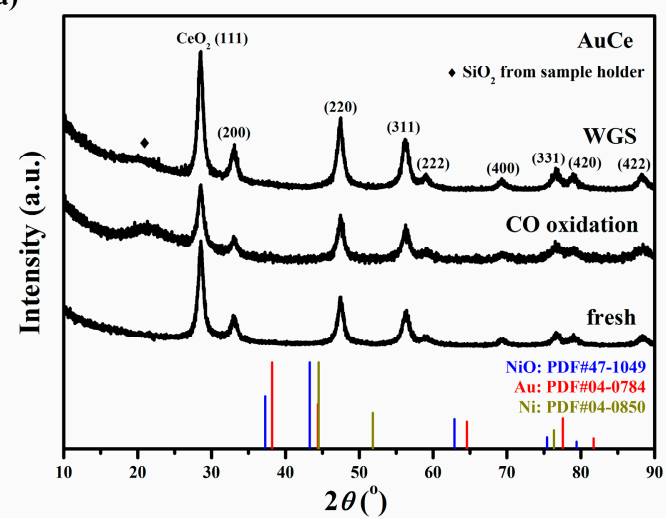

(b)

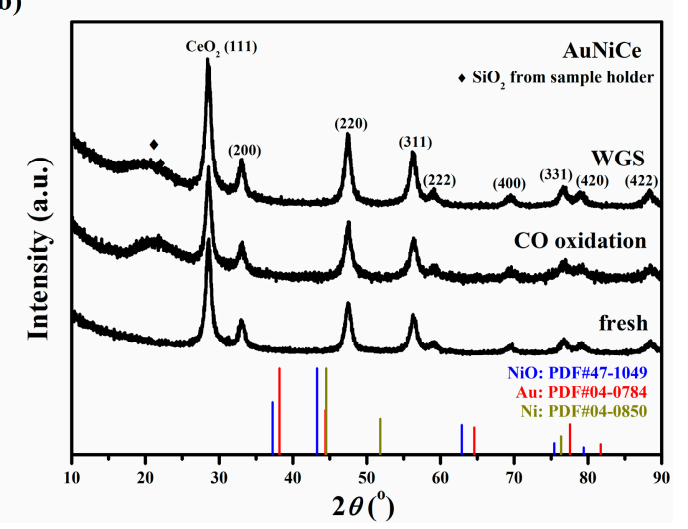

Figure 5. XRD patterns of $\mathrm{AuNi} / \mathrm{CeO}_{2}$ samples before and after different reactions: (a) AuCe; (b) AuNiCe. 
Crystal structures of ceria supported gold-nickel samples after both CO oxidation and WGS reactions were also determined by XRD. Figure 5 exhibit that the all the measured catalysts maintained the pure $f c c$ ceria phase as that of fresh catalyst. Still, no patterns of $\mathrm{Au}$ or $\mathrm{Ni} / \mathrm{NiO}$ were detected and the lattice constants $(a)$ of used catalysts are similar to those of fresh (see Table 1), revealing the relatively stable gold and nickel species during these two reactions [36,37] and/or low contents of gold and nickel.

The HRTEM images of used $\mathrm{Au} / \mathrm{CeO}_{2}$ and $\mathrm{AuNi} / \mathrm{CeO}_{2}$ samples in Figure $6 \mathrm{a}, \mathrm{c}, \mathrm{e}, \mathrm{g}$ determine the presence of $f c c \mathrm{CeO}_{2}$ phase in both AuCe and AuNiCe after either $\mathrm{CO}$ oxidation or WGS reactions. The corresponding STEM-EDS mapping results in Figure $6 \mathrm{~d}, \mathrm{f}, \mathrm{h}$ verify the well dispersion of gold after reaction for the tested $\mathrm{AuNi} / \mathrm{CeO}_{2}$ catalysts, except that $\sim 5 \mathrm{~nm}$ Au nanoparticles appeared for AuCe after $\mathrm{CO}$ oxidation (Figure 6b), indicating the agglomeration of small-size gold species under $\mathrm{CO}+\mathrm{O}_{2}$ working conditions without the addition of nickel.
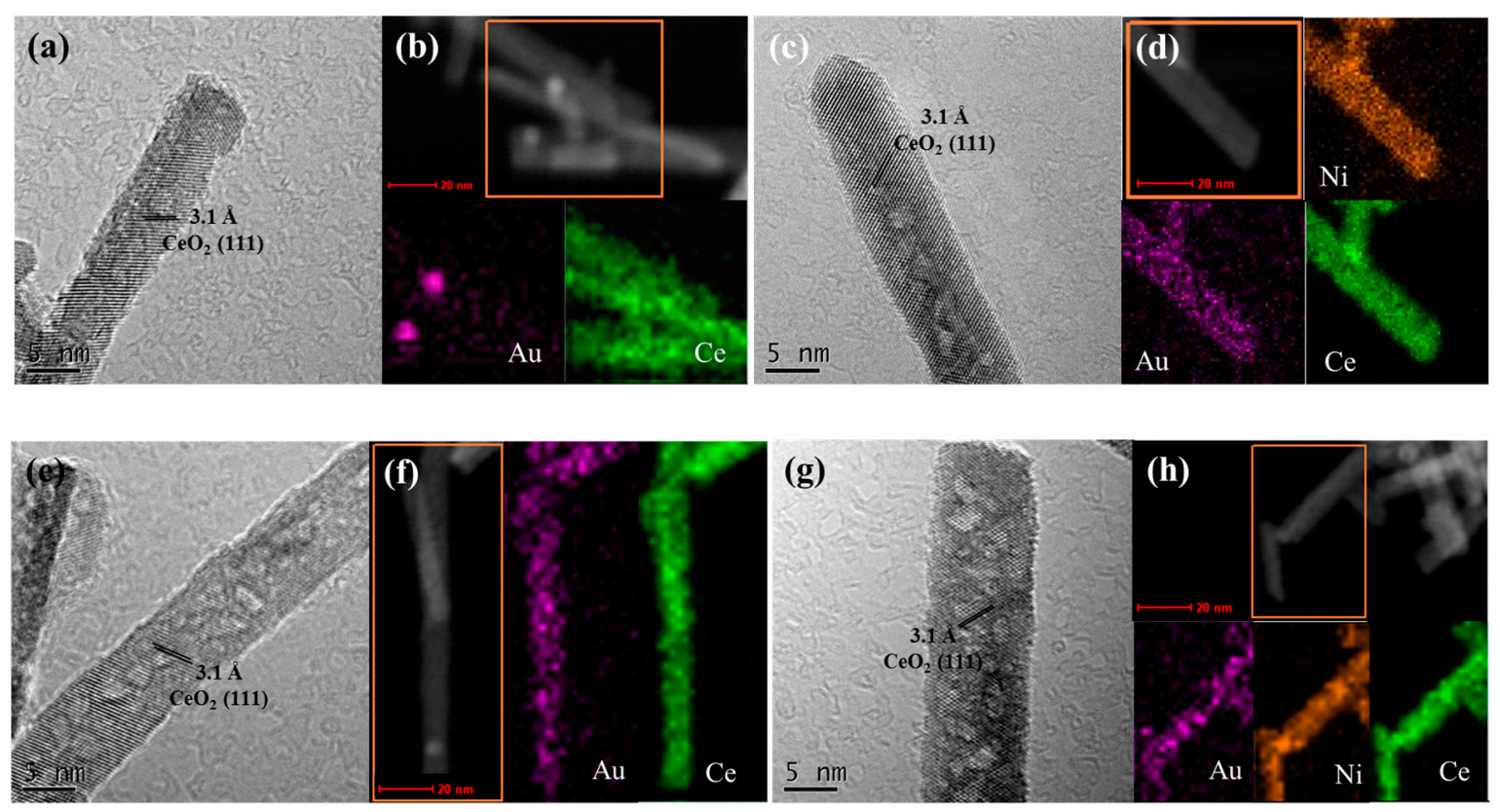

Figure 6. HRTEM images (a,c,e,g) and STEM-EDS mapping results $(\mathbf{b}, \mathbf{d}, \mathbf{f}, \mathbf{h})$ of used $\mathrm{AuNi} / \mathrm{CeO}_{2}$ samples after CO oxidation (a-d) and WGS (e-h) reactions: (a,b,e,f) AuCe; (c,d,g,h) AuNiCe.

\subsection{Electronic Structure of Gold and Nickel for Ceria-Supported Catalysts}

X-ray absorption near edge structure (XANES) spectroscopy was carried out to determine the electronic structure of Au in this work. Seen in Figure 7a,b, the oxidation of gold was totally different between $\mathrm{AuCe}$ and $\mathrm{AuNiCe}$. We have run linear combination fits, and obtained the average valence states of gold to be +0.3 and +1.7 for fresh AuCe (Figure 7c) and AuNiCe (Figure 7d), respectively. Clearly, with the addition of secondary metal $(\mathrm{Ni})$, the oxidized gold species become dominant on the ceria surface. Figure 7 also depicts the totally different XANES profiles of Au L3 edge for used catalysts from those of fresh samples. The intensity of white-line of AuCe sample slightly oxidized after CO oxidation reaction, but obviously decreased after WGS reaction (Figure 7a). For the AuNiCe sample, the intensity of white-line drastically decreased after both CO oxidation and WGS reactions (Figure $7 \mathrm{~b}$ ). It is worthwhile mentioning that the Au still obtained oxidized after $\mathrm{CO}$ oxidation, but almost equal to pure $\mathrm{Au}$ foil $\left(\mathrm{Au}^{0}\right)$ after WGS reaction [38,39], whatever nickel is doped or not. It reveals that the reaction conditions of $\mathrm{CO}+\mathrm{H}_{2} \mathrm{O}$ significantly reduce more fraction of gold species supported on the ceria surface than those of $\mathrm{CO}+\mathrm{O}_{2}$. 
(a)

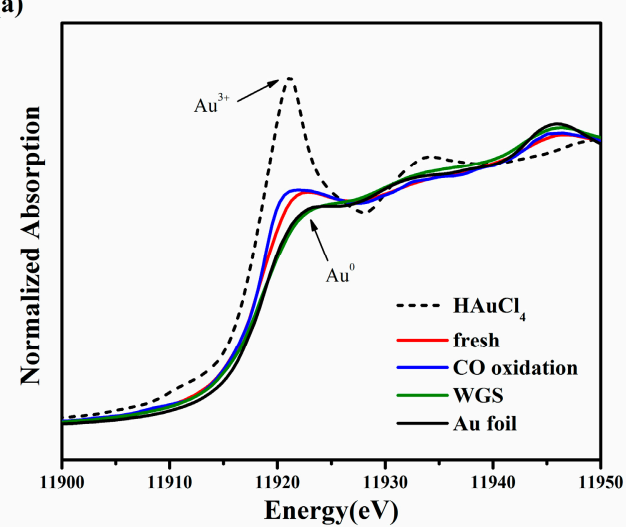

(c)

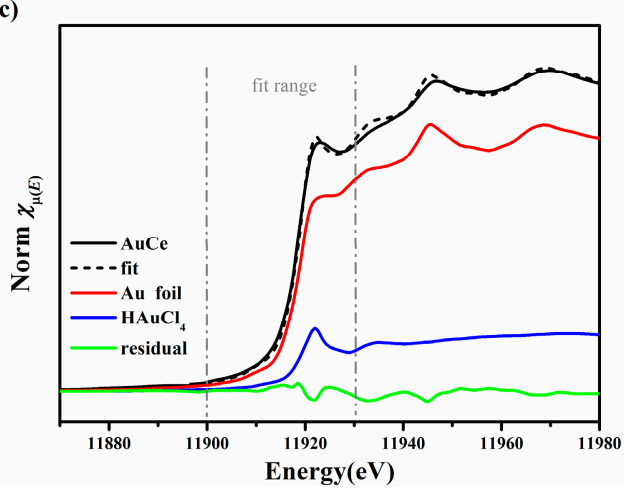

(b)

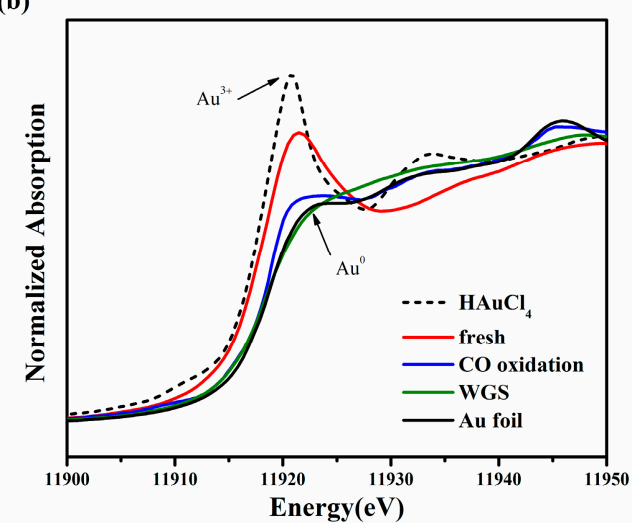

(d)

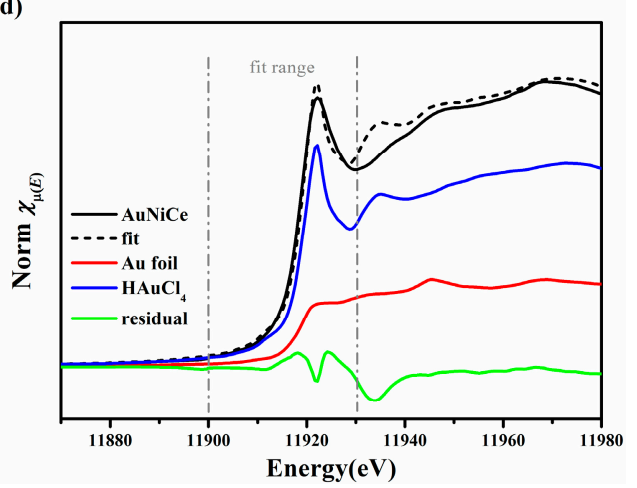

Figure 7. XANES profiles of $\mathrm{AuNi} / \mathrm{CeO}_{2}$ samples before and after different reactions: (a) AuCe; (b) AuNiCe; (c) linear combination fit on fresh AuCe; (d) linear combination fit on fresh AuNiCe.

Owing to the influence of intensive fluorescence of $\mathrm{Ce}$, the Ni edge cannot be measured by XAFS. Here, we applied X-ray photoelectron spectroscopy (XPS) to verify the electronic structure of nickel. Figure 8a exhibits that the unique $\mathrm{Ni}^{2+}$ species for the nickel-containing samples, whether before or after the catalytic tests. Table 1 displays that the surface concentration of nickel (fresh: 4.5 at $\%$; used in CO oxidation: 3.8 at $\%$; used in WGS: 4.3 at $\%$ ) is almost identical the bulk concentration of nickel (3.9 at $\%)$, manifesting no nickel segregation on the surface of ceria nanorods. Besides, Figure 8a exhibits that the valence of nickel for all the used samples was remained as $\mathrm{Ni}^{2+}$ after either $\mathrm{CO}$ oxidation or WGS reaction. Thus, the nickel species did not change their electronic structure during reaction. In another word, the state of gold is more important to the catalytic reactivity of our $\mathrm{AuNi} / \mathrm{CeO}_{2}$ samples.

The temperature-programmed reduction by hydrogen $\left(\mathrm{H}_{2}\right.$-TPR) was performed to investigate the reducibility and metal-support interaction for the ceria-supported gold-nickel catalysts. Figure $8 \mathrm{~b}$ exhibits that no observable reduction was found for pure ceria nanorods, and the peaks at 184 and $257^{\circ} \mathrm{C}$ for $\mathrm{NiCe}$ can be assigned to the reduction of surface oxygen species of $\mathrm{CeO}_{2}$ and $\mathrm{Ni}^{\delta+}$ species interacting with the $\mathrm{CeO}_{2}[36,40]$. A broad reduction bands at $118{ }^{\circ} \mathrm{C}$ for the $\mathrm{AuCe}$, which can be attributed to the $\mathrm{Au}^{\delta+}$ species interacting with $\mathrm{CeO}_{2}$ [7], Remarkably, the reduction peaks for the AuCe was maintained but shifted to higher temperature after the addition of nickel (Figure $8 \mathrm{~b}$ and Table 2), possibly due to the stronger interaction between nickel-modified gold and ceria support [36]. Similarly, the reduction temperatures for nickel-containing species were also much lower in AuNiCe than the gold-free NiCe sample, revealing the interaction between gold and nickel oxide to form Au-O-Ni structure. The $\mathrm{H}_{2}$ consumption values of all the tested samples are listed in Table 2. It must be mentioned that the real consumption of $\mathrm{H}_{2}$ in experiment is significantly higher than those theoretical (only considering $\mathrm{Au}^{\delta+} \rightarrow \mathrm{Au}^{0}$ and $\mathrm{Ni}^{2+} \rightarrow \mathrm{Ni}^{0}$ ). This could be explained by the partial reduction of ceria support $\left(\mathrm{Ce}^{4+} \rightarrow \mathrm{Ce}^{3+}\right)$ starting around $100{ }^{\circ} \mathrm{C}$, which is activated by either gold or nickel oxide 
species. On the basis of the above $\mathrm{H}_{2}$-TPR results, we can identify the interactions of both metal to support and gold to nickel in our study.

(a)

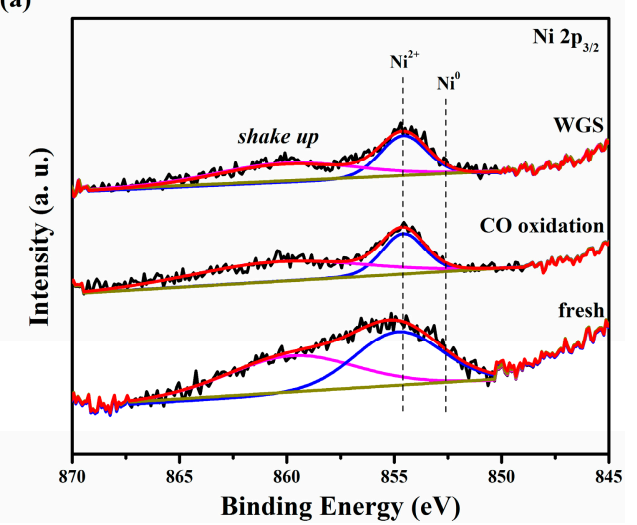

(b)

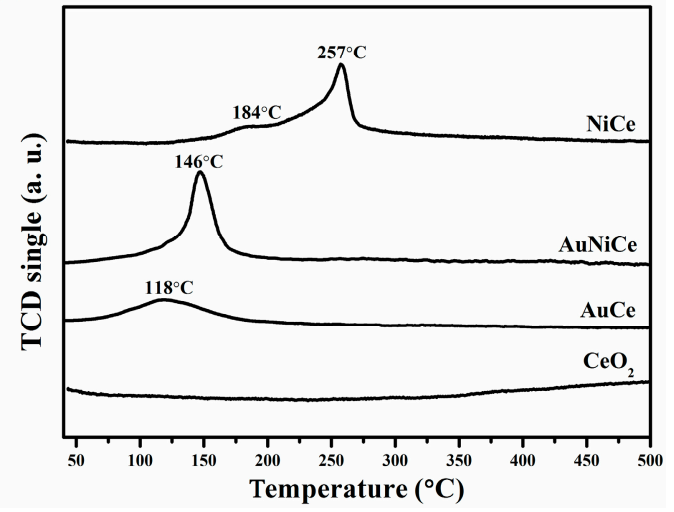

Figure 8. (a) XPS spectra of $\mathrm{Ni} 2 \mathrm{p}$ for AuNiCe; (b) $\mathrm{H}_{2}$-TPR profiles for fresh $\mathrm{AuNi} / \mathrm{CeO}_{2}$ samples.

\section{Discussion}

\subsection{Effect of Nickel Oxide to Gold-Ceria Catalyst for CO Oxidation Reaction}

It is generally accepted that $\mathrm{Ni}$ deposited on the $\mathrm{CeO}_{2}$ has supremely low even hardly any activity for $\mathrm{CO}$ oxidation reaction between 20 and $120^{\circ} \mathrm{C}[37,40,41]$, and we also observed the same results during the catalytic tests (NiCe, Figure $4 \mathrm{a}$ ). Hence, the reactivity of investigated catalysts in this work should be correlated to the structural and textural properties of gold itself. Previously, Deng et. al reported the metallic $\mathrm{Au}^{0}$ species favor the $\mathrm{CO}$ oxidation reaction in $\mathrm{Au}-\mathrm{Ce}-\mathrm{O}$ and $\mathrm{Au}-\mathrm{Fe}-\mathrm{O}$ systems, which was demonstrated by the comparison between different states (oxidation pretreatment and reduction pretreatment) for the catalytic measurements [14]. In our study, we found the distinct structural changes of gold when nickel was introduced, and thus the two samples (AuCe and AuNiCe) show obvious differences in activity for CO oxidation process. Combining the XANES results on gold, we confirmed that the fraction of metallic Au decreased, as well as the activity of samples decreased with the addition of nickel, which is in a good agreement with the argument that metallic gold is active species for CO oxidation [21]. Here, we emphasized the importance of comparison on normalized reaction rate $(r)$ by gold amount to exclude the variation on the Au concentration in each sample (Table 2). In one word, metallic gold is indeed active for the low-temperature CO oxidation reaction.

\subsection{Effect of Nickel Oxide to Gold-Ceria Catalyst for Water-Gas Shift Reaction}

On the other hand, for the investigated WGS reaction, we found a totally contrast phenomenon towards the $\mathrm{CO}$ oxidation reaction. First, NiCe has catalytic reactivity for this reaction, but very limited below $300^{\circ} \mathrm{C}$ (Figure $4 \mathrm{~b}$ ). We have determined a clear conclusion on the order of WGS activity: AuNiCe $>$ AuCe $>$ NiCe (Figure 4 b), especially for the low-temperature (up to $300{ }^{\circ} \mathrm{C}$ ) reaction. Here, according to our XANES data (Figure $7 \mathrm{~b}$ ), the ionic gold species, which was promoted by the addition of nickel component, benefit the catalytic performance of ceria supported catalysts for the WGS reaction. Analogously, Fu et al. removed the gold particles with $\mathrm{NaCN}$ aqueous solution leaching and remained very fine clusters or atomically dispersed gold which were identified as ionic $\mathrm{Au}$, and such gold species were proved to be very important to WGS reaction [22]. Later on, considerable researchers have been devoted to the cationic gold are the active species [7,22]. In this work, we designed another approach and prepared two samples with totally different oxidation state of $\mathrm{Au}$ by the addition of nickel, and compared the activity of ceria-supported gold catalysts with after the normalization by gold amount. Finally, we disclosed that the normalized reaction rate increased with the decreased fraction of ionic gold in Au-Ni-Ce-O system (Table 2). However, the XANES results on used samples indicate the reduction of ionic $\mathrm{Au}^{\delta+}$ species during the WGS reaction, especially for 
AuNiCe (Figure $7 \mathrm{~b}$ ). It indicates that the ionic gold species were converted to dominantly metallic $\mathrm{Au}$ during WGS. However, the initial small-size $\mathrm{Au}^{\delta+}$ species interacting with either nickel oxide (Au-O-Ni) or ceria support (Au-O-Ce) effectively kept the active gold atoms/clusters survived after the catalytic measurement, and thus held the high reactivity on WGS, which is well consistent with our previous findings demonstrated by in-situ XAFS results [42].

In this work, there was no special treatment between the end of catalytic tests and the structural characterization of XANES on gold. Since the as-formed metallic $\mathrm{Au}^{0}$ component from ionic $\mathrm{Au}^{\delta+}$ species under WGS reaction conditions is not easy to be reoxidized by air in room temperature (actually $400{ }^{\circ} \mathrm{C}$ was required revealed by in-situ XAFS and cyclic $\mathrm{H}_{2}$-TPR) previously [42], we believe the used catalysts after these two reactions (considering the reducing potential in $\mathrm{CO}$ oxidation is much lower than that in WGS) should largely maintained their structural evolution completed during the catalytic tests.

\section{Materials and Methods}

\subsection{Raw Materials}

All the reagents used in this work were purchased from Sinopharm Chemical Reagent Co., all of which were analytical grade and without purified any more.

\subsection{Preparation of Ceria Nanorods}

The $\mathrm{CeO}_{2}$ nanorods synthesized by hydrothermal approach [13]. $\mathrm{Ce}\left(\mathrm{NO}_{3}\right)_{3} \cdot 6 \mathrm{H}_{2} \mathrm{O}(0.05 \mathrm{~mol} / \mathrm{L})$ was added into $\mathrm{NaOH}(6 \mathrm{~mol} / \mathrm{L})$ solution $(70 \mathrm{~mL})$ with vigorous stirring about $15 \mathrm{~min}$. The suspension was moved into Teflon bottle (inner volume: $100 \mathrm{~mL}$ ) and then tightly seal in stainless-steel autoclave. Hydrothermal treatment operated at $100{ }^{\circ} \mathrm{C}$ for $24 \mathrm{~h}$. Then, the precipitates were washed by Millipore (>18 M $\Omega$ ) water (ca. $1000 \mathrm{~mL}$ ) four times and alcohol (ca. $250 \mathrm{~mL}$ ) once. The as-washed ceria nanorods were dried in vacuum under $70^{\circ} \mathrm{C}$ for $12 \mathrm{~h}$.

\subsection{Preparation of Gold-Nickel Cluster on Ceria}

Ceria supported gold-nickel catalyst were synthesized according to deposition-precipitation (DP) method. The atomic percentage of gold was designed to be $1 \mathrm{at} \%$, the nickel was adjusted to be 5 at. $\%$. The $\mathrm{NaHCO}_{3}(8.4 \mathrm{~g})$ and calcined ceria nanorods $(1 \mathrm{~g})$ were stirred in $180 \mathrm{~mL}$ Millipore $(>18 \mathrm{M} \Omega)$ water to form a buffering solution with $\mathrm{pH}$ value of $\sim 9$. $\mathrm{HAuCl}_{4} \cdot 4 \mathrm{H}_{2} \mathrm{O}$ and $\mathrm{Ni}\left(\mathrm{NO}_{3}\right)_{2} \cdot 6 \mathrm{H}_{2} \mathrm{O}$ were dissolved in $20 \mathrm{~mL}$ Millipore water and then slowly dropped into the above stock solution, and still aged at room temperature for $1 \mathrm{~h}$. The precipitates were separated by centrifugation and washed by Millipore water for three times. The as-washed powders were dried in vacuum at $65^{\circ} \mathrm{C}$ for $12 \mathrm{~h}$ and further calcined in air at $400{ }^{\circ} \mathrm{C}$ for $4 \mathrm{~h}$ (heating rate: $2{ }^{\circ} \mathrm{C} / \mathrm{min}$ ). The prepared ceria-supported gold-nickel clusters were denoted as AuCe and AuNiCe for single metal and bimetallic samples, respectively.

\subsection{Characterizations}

The experimental concentration of gold and nickel were detected by inductively coupled plasma atomic emission spectroscopy (ICP-AES) with IRIS Intrepid II XSP instrument (Thermo Electron Co., Waltham, MA, USA).

The nitrogen adsorption-desorption characterizations were analyzed on an ASAP2020-HD88 analyzer (Micromeritics Co., Ltd., Atlanta, GA, USA) at $77 \mathrm{~K}$. The as-calcined powders were degassed at $250{ }^{\circ} \mathrm{C}$ under vacuum $(<100 \mathrm{~mm} \mathrm{Hg})$ over $4 \mathrm{~h}$ before the introduction of $\mathrm{N}_{2}$. The pore size $\left(r_{\mathrm{p}}\right)$ distribution of each sample was calculated on the basis of desorption branch of the tested isotherms with the BJH method. The BET specific surface areas $\left(S_{\mathrm{BET}}\right)$ were counted from data between 0.05 and 0.20 in the relative pressure.

The powder X-ray diffraction (XRD) patterns were experimented on Bruker D8 Advance diffractometer (Bruker Co., Billerica, MA, USA) (40 kV, $40 \mathrm{~mA})$ using $\mathrm{Cu} K \alpha_{1}$ radiation $(\lambda=1.5406 \AA)$, 
with a scanning rate of $4^{\circ} / \mathrm{min}$. The $2 \theta$ angles were calibrated with a $\mu \mathrm{m}$-scale alumina $\left(\alpha-\mathrm{Al}_{2} \mathrm{O}_{3}\right)$ standard. The diffraction patterns of samples were gathered from 10 to $90^{\circ}$ with $0.02^{\circ} /$ step. The ground sample was planished on a quartz sample holder before each test. Cell dimensions of cubic $\mathrm{CeO}_{2}$ were obtained from the corresponding powder data with the "LAPOD" software of least-squares refinement by Cohen's method [43,44].

The transmission electron microscopy (TEM), high-resolution transmission electron microscopy (HRTEM) images and scanning transmission electron microscopy-energy dispersive spectrometer (STEM-EDS) elemental mapping results were obtained from a FEI Tecnai G2 F20 microscope (FEI Co., Hillsboro, TX, USA) executing at $200 \mathrm{kV}$, equipped with a Genesis XM2 accessory (EDAX Inc., Mahwah, NJ, USA). Samples were ultrasonic dispersed in absolute alcohol about $5 \mathrm{~min}$, and then placed a drop of liquid supernatant on an ultra-thin ( $3-5 \mathrm{~nm}$ ) carbon film-coated $\mathrm{Cu}$ grid. The sample grid was dried spontaneously under dark conditions before inserted into the sample holder.

The X-ray photoelectron spectroscopy (XPS) measurements were performed on an Axis Ultra XPS

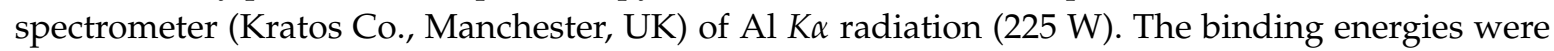
calibrated by $\mathrm{C} 1 \mathrm{~s}$ line at $284.8 \mathrm{eV}$.

\subsection{X ray Absorption Fine Structure}

The X-ray absorption fine structure (XAFS) spectroscopy at the Au L3 $\left(E_{0}=11919 \mathrm{eV}\right)$ edge was operated at $3.5 \mathrm{GeV}$ in "top-up" mode with a constant current of $260 \mathrm{~mA}$ at the BL14W1 beamline [45] of the Shanghai Synchrotron Radiation Facility (SSRF). The XAFS data were collected with a 7-element Ge solid state detector in fluorescence mode. The X-ray energy was calibrated with the absorption edge of pure Au foil. Before the XAFS measurement, we ground the investigated sample into fine powders (smaller than $200 \mathrm{mesh}$ ), and then pressed the pure sample without any dilution to a solid pellet.

The profiles of X-ray absorption near edge structure (XANES) part were pretreated and fitted with Athena software. The "normalized absorption" was defined as experimental absorption coefficients as a function of energies $\mu(E)$ were processed by background subtraction and normalization procedures. The chemical valence of Au was determined with the linear combination fit [46] by comparison to the corresponding references of $\mathrm{Au}$ foil and $\mathrm{HAuCl}_{4}$ based on the normalized XANES profiles in Athena software.

\subsection{Catalytic Tests}

The reducibility of samples were probed with temperature-programmed reduction by hydrogen $\left(\mathrm{H}_{2}\right.$-TPR) operated in a Builder PCA-1200 instrument (BJBUILDER Optics Co., Ltd., Beijing, China), and the consumption of hydrogenation determined with a thermal conductivity detector (TCD) (BJBUILDER Optics Co., Ltd., Beijing, China). The $30 \mathrm{mg}$ laminar and sieved samples (40-60 mesh) were initially oxidized in pure $\mathrm{O}_{2}$ at $300{ }^{\circ} \mathrm{C}$ for $30 \mathrm{~min}$ and cooled naturally to room temperature before reduction. The reduction process was performed with a gas mixture of $5 \mathrm{vol} \% \mathrm{H}_{2} / \mathrm{Ar}$ (Jinan Deyang Co., Jinan, China, $99.997 \%$ purity) from room temperature to $500{ }^{\circ} \mathrm{C}$ (flowing rate: $30 \mathrm{~mL} / \mathrm{min}$; heating rate: $5^{\circ} \mathrm{C} / \mathrm{min}$ ).

The catalytic test for $\mathrm{CO}$ oxidation reaction over ceria-supported gold-nickel samples were estimated in a plug flow reactor, in which the thermocouple is placed on the top of the samples and connected with a PID controller (YUDIAN Co., Xiamen, China). The variations of $\mathrm{CO}$ and $\mathrm{CO}_{2}$ in outlets were monitored by a non-dispersive Gasboard 3500 IR spectroscopy (Wuhan Sifang Co., Wuhan, China). The $50 \mathrm{mg}$ of sieved (40-60 mesh) samples were pretreated in air at $300{ }^{\circ} \mathrm{C}$ for $30 \mathrm{~min}$ before test and cooled down to room temperature in pure $\mathrm{N}_{2}$. Then, a gas mixture of $1 \mathrm{vol} . \% \mathrm{CO} / 20 \mathrm{vol} \%$ $\mathrm{O}_{2} / \mathrm{N}_{2}$ (99.997\% purity, Jinan Deyang Co., Jinan, China) passed through the catalysts at a flow rate of $67 \mathrm{~mL} / \mathrm{min}$, corresponding to a space velocity of $80,000 \mathrm{~mL} \cdot \mathrm{h}^{-1} \mathrm{~g}_{\mathrm{cat}}{ }^{-1}$. The "light off" profiles were obtained with the changes of $\mathrm{CO}$ conversions from 20 to $150{ }^{\circ} \mathrm{C}$ with a ramping rate of $3{ }^{\circ} \mathrm{C} / \mathrm{min}$. The whole measurement of $\mathrm{CO}$ oxidation reaction took ca. $43 \mathrm{~min}$. The $\mathrm{CO}$ conversion was calculated with the following equations: $\mathrm{CO}$ conversion $(\%)=\left(\mathrm{CO}_{\text {in }}-\mathrm{CO}_{\text {out }}\right) / \mathrm{CO}_{\text {in }} \times 100$. In the kinetic experiments, 
the reaction rates were calculated on the basis of data points of less than $20 \% \mathrm{CO}$ conversions to exclude the mass transfer limitation.

The catalytic test of water gas shift (WGS) reaction activities were evaluated in the plug flow reactor, and the thermocouple was placed on the top of the catalysts and connected with a PID controller. All outlet gases were monitored by a Gasboard 3500 IR spectroscopy (Wuhan Sifang Co., Wuhan, China). $50 \mathrm{mg}$ of sieved (40-60 mesh) sample was pretreated with $5 \% \mathrm{H}_{2}$ / Ar gas mixture at $300{ }^{\circ} \mathrm{C}$ for $30 \mathrm{~min}$. The reactant gas consisting of 2 vol. $\% \mathrm{CO} / \mathrm{N}_{2}$ (99.997\% purity, Jinan Deyang Co., Jinan, China) was fed to mix with water vapor $\left(\mathrm{CO}: \mathrm{H}_{2} \mathrm{O}=1: 5\right)$ at a flow rate of $70 \mathrm{~cm}^{3} / \mathrm{min}$ with a total GHSV of $84,000 \mathrm{~cm}^{3} \mathrm{~g}^{-1} \mathrm{~h}^{-1}$. The reactant temperature began from $150{ }^{\circ} \mathrm{C}$ to $400{ }^{\circ} \mathrm{C}$ under the heating rate $5{ }^{\circ} \mathrm{C} / \mathrm{min}$ and the catalytic data were recorded at $50^{\circ} \mathrm{C}$ per step. The whole measurement of WGS reaction took 7-8 h. The CO conversion of WGS is calculated according to the following equation: $\mathrm{CO}$ conversion $(\%)=\left(\mathrm{CO}_{\text {in }}-\mathrm{CO}_{\text {out }}\right) / \mathrm{CO}_{\text {in }} \times 100$. In the kinetic experiments, the reaction rates were calculated on the basis of data points of less than $20 \% \mathrm{CO}$ conversions to exclude the mass transfer limitation.

\section{Conclusions}

In this work, gold-ceria catalysts doped with nickel were synthesized by the depositionprecipitation method. The use of $\mathrm{NaHCO}_{3}$ as precipitating agent drove part of the gold species off from the ceria surface. The corresponding catalytic tests demonstrated that the addition of nickel shows positive effect to the WGS reaction, while negative effect to the $\mathrm{CO}$ oxidation reaction. On the basis of multiple characterization means including XRD, XPS, XANES and TEM/HRTEM, we verified that the ionic gold may benefit WGS process and the metallic gold may promote the reactivity of gold-ceria catalyst for the $\mathrm{CO}$ oxidation reaction. Furthermore, the main contribution of nickel oxide is to tune the electronic structure of active gold species.

Author Contributions: R.S. conceived and designed the experiments; M.S. performed the experiments and analyzed the data; S.W. and D.-L.W. contributed part of catalytic measurements; M.S., R.S. and C.-J.J. wrote the paper.

Funding: Financial supported from the National Science Foundation of China (NSFC) (grant nos. 21773288 and 21331001), the Excellent Young Scientists Fund from NSFC (grant no. 21622106), the Outstanding Scholar Fund (grant nos. JQ201703) from the Science Foundation of Shandong Province (China), the Taishan Scholar Project of Shandong Province (China).

Conflicts of Interest: The authors declare no conflict of interest.

\section{References}

1. Carrettin, S.; Concepcion, P.; Corma, A.; Lopez Nieto, J.M.; Puntes, V.F. Nanocrystalline $\mathrm{CeO}_{2}$ increases the activity of $\mathrm{Au}$ for $\mathrm{CO}$ oxidation by two orders of magnitude. Angew. Chem. Int. Ed. 2004, 43, 2538-2540. [CrossRef] [PubMed]

2. Herzing, A.A.; Kiely, C.J.; Carley, A.F.; Landon, P.; Hutchings, G.J. Identification of active gold nanoclusters on iron oxide supports for CO oxidation. Science 2008, 321, 1331-1335. [CrossRef] [PubMed]

3. Li, X.N.; Yuan, Z.; He, S.G. CO oxidation promoted by gold atoms supported on titanium oxide cluster anions. J. Am. Chem. Soc. 2014, 136, 3617-3623. [CrossRef] [PubMed]

4. Li, Z.Y.; Yuan, Z.; Li, X.N.; Zhao, Y.X.; He, S.G. CO oxidation catalyzed by single gold atoms supported on aluminum oxide clusters. J. Am. Chem. Soc. 2014, 136, 14307-14313. [CrossRef] [PubMed]

5. Guo, Y.; Gu, D.; Jin, Z.; Du, P.P.; Si, R.; Tao, J.; Xu, W.Q.; Huang, Y.Y.; Senanayake, S.; Song, Q.S.; et al. Uniform $2 \mathrm{~nm}$ gold nanoparticles supported on iron oxides as active catalysts for CO oxidation reaction: Structure-activity relationship. Nanoscale 2015, 7, 4920-4928. [CrossRef] [PubMed]

6. Centeno, M.; Ramírez Reina, T.; Ivanova, S.; Laguna, O.; Odriozola, J. Au/ $\mathrm{CeO}_{2}$ Catalysts: Structure and CO Oxidation Activity. Catalysts 2016, 6, 158. [CrossRef]

7. Si, R.; Flytzani-Stephanopoulos, M. Shape and crystal-plane effects of nanoscale ceria on the activity of $\mathrm{Au}-\mathrm{CeO}_{2}$ catalysts for the water-gas shift reaction. Angew. Chem. Int. Ed. 2008, 47, 2884-2887. [CrossRef] [PubMed] 
8. Rim, K.T.; Eom, D.; Chan, S.W.; Flytzani-Stephanopoulos, M.; Flynn, G.W.; Wen, X.D.; Batista, E.R. Scanning tunneling microscopy and theoretical study of water adsorption on $\mathrm{Fe}_{3} \mathrm{O}_{4}$ : Implications for catalysis. J. Am. Chem. Soc. 2012, 134, 18979-18985. [CrossRef] [PubMed]

9. Yang, M.; Allard, L.F.; Flytzani-Stephanopoulos, M. Atomically dispersed Au- $(\mathrm{OH})_{\mathrm{x}}$ species bound on titania catalyze the low-temperature water-gas shift reaction. J. Am. Chem. Soc. 2013, 135, 3768-3771. [CrossRef] [PubMed]

10. Yang, M.; Li, S.; Wang, Y.; Herron, J.A.; Xu, Y.; Allard, L.F.; Lee, S.; Huang, J.; Mavrikakis, M.; Flytzani-Stephanopoulos, M. Catalytically active $\mathrm{Au}-\mathrm{O}(\mathrm{OH})_{\mathrm{x}}$ - species stabilized by alkali ions on zeolites and mesoporous oxides. Science 2014, 346, 1498-1501. [CrossRef] [PubMed]

11. Yao, S.; Zhang, X.; Zhou, W.; Gao, R.; Xu, W.; Ye, Y.; Lin, L.; Wen, X.; Liu, P.; Chen, B.; et al. Atomic-layered Au clusters on $\alpha-\mathrm{MoC}$ as catalysts for the low-temperature water-gas shift reaction. Science 2017, 357, 389-393. [CrossRef] [PubMed]

12. Flytzani-Stephanopoulos, M. Gold atoms stabilized on various supports catalyze the water-gas shift reaction. Acc. Chem. Res. 2014, 47, 783-792. [CrossRef] [PubMed]

13. Mai, H.X.; Sun, L.D.; Zhang, Y.W.; Si, R.; Feng, W.; Zhang, H.P.; Liu, H.C.; Yan, C.H. Shape-Selective Synthesis and Oxygen Storage Behavior of Ceria Nanopolyhedra, Nanorods, and Nanocubes. J. Phys. Chem. B 2005, 109, 24380-24385. [CrossRef] [PubMed]

14. Deng, W.; Carpenter, C.; Yi, N.; Flytzani-Stephanopoulos, M. Comparison of the activity of $\mathrm{Au} / \mathrm{CeO}_{2}$ and $\mathrm{Au} / \mathrm{Fe}_{2} \mathrm{O}_{3}$ catalysts for the $\mathrm{CO}$ oxidation and the water-gas shift reactions. Top. Catal. 2007, 44, 199-208. [CrossRef]

15. Huang, X.S.; Sun, H.; Wang, L.C.; Liu, Y.M.; Fan, K.N.; Cao, Y. Morphology effects of nanoscale ceria on the activity of $\mathrm{Au} / \mathrm{CeO}_{2}$ catalysts for low-temperature CO oxidation. Appl. Catal. B 2009, 90, 224-232. [CrossRef]

16. Lai, S.; Qiu, Y.; Wang, S. Effects of the structure of ceria on the activity of gold/ceria catalysts for the oxidation of carbon monoxide and benzene. J. Catal. 2006, 237, 303-313. [CrossRef]

17. Shekhar, M.; Wang, J.; Lee, W.S.; Williams, W.D.; Kim, S.M.; Stach, E.A.; Miller, J.T.; Delgass, W.N.; Ribeiro, F.H. Size and support effects for the water-gas shift catalysis over gold nanoparticles supported on model $\mathrm{Al}_{2} \mathrm{O}_{3}$ and $\mathrm{TiO}_{2}$. J. Am. Chem. Soc. 2012, 134, 4700-4708. [CrossRef] [PubMed]

18. Janssensa, T.V.W.; Clausena, B.S.; Hvolbækb, B.; Falsigc, H.; Christensenc, C.H.; Bligaardb, T.; Nørskov, J.K. Insights into the reactivity of supported Au nanoparticles: Combining theory and experiments. Top. Catal. 2007, 44, 15-26. [CrossRef]

19. Chen, S.; Luo, L.; Jiang, Z.; Huang, W. Size-Dependent Reaction Pathways of Low-Temperature CO Oxidation on $\mathrm{Au} / \mathrm{CeO}_{2}$ Catalysts. ACS Catal. 2015, 5, 1653-1662. [CrossRef]

20. Taketoshi, A.; Haruta, M. Size- and Structure-specificity in Catalysis by Gold Clusters. Chem. Lett. 2014, 43, 380-387. [CrossRef]

21. Guo, L.W.; Du, P.P.; Fu, X.P.; Ma, C.; Zeng, J.; Si, R.; Huang, Y.Y.; Jia, C.J.; Zhang, Y.W.; Yan, C.H. Contributions of distinct gold species to catalytic reactivity for carbon monoxide oxidation. Nat. Commun. 2016, 7, 13481. [CrossRef] [PubMed]

22. Fu, Q.; Saltsburg, H.; Flytzani-Stephanopoulos, M. Active Nonmetallic Au and Pt Species on Ceria-Based Water-Gas Shift Catalysts. Science 2003, 301, 935-938. [CrossRef] [PubMed]

23. Scott, R.W.J.; Sivadinarayana, C.; Wilson, O.M.; Yan, Z.; Goodman, D.W.; Crooks, R.M. Titania-Supported PdAu Bimetallic Catalysts Prepared from Dendrimer-Encapsulated Nanoparticle Precursors. J. Am. Chem. Soc. 2005, 127, 1380-1381. [CrossRef] [PubMed]

24. Frenkel, A.I.; Machavariani, V.S.; Rubshtein, A.; Rosenberg, Y.; Voronel, A.; Stern, E.A. Local structure of disordered Au-Cu and Au-Ag alloys. Phys. Rev. B 2000, 62, 9364-9371. [CrossRef]

25. Eveline, B.; van, B.J.A. Electronic and Geometric Structures of Supported Platinum, Gold, and Platinum-Gold Catalysts. J. Phys. Chem. C 2007, 111, 9761-9768.

26. Liu, X.; Wang, A.; Zhang, T.; Su, D.-S.; Mou, C.-Y. Au-Cu alloy nanoparticles supported on silica gel as catalyst for CO oxidation: Effects of Au/Cu ratios. Catal. Today 2011, 160, 103-108. [CrossRef]

27. He, P.; Wang, X.; Liu, Y.; Liu, X.; Yi, L. Comparison of electrocatalytic activity of carbon-supported Au-M $(\mathrm{M}=\mathrm{Fe}, \mathrm{Co}, \mathrm{Ni}, \mathrm{Cu}$ and $\mathrm{Zn})$ bimetallic nanoparticles for direct borohydride fuel cells. Int. J. Hydrog. Energy 2012, 37, 11984-11993. [CrossRef]

28. Qiao, B.; Wang, A.; Yang, X.; Allard, L.F.; Jiang, Z.; Cui, Y.; Liu, J.; Li, J.; Zhang, T. Single-atom catalysis of CO oxidation using $\mathrm{Pt}_{1} / \mathrm{FeO}_{\mathrm{x}}$. Nat. Chem. 2011, 3, 634-641. [CrossRef] [PubMed] 
29. Wei, H.; Liu, X.; Wang, A.; Zhang, L.; Qiao, B.; Yang, X.; Huang, Y.; Miao, S.; Liu, J.; Zhang, T. FeOx-supported platinum single-atom and pseudo-single-atom catalysts for chemoselective hydrogenation of functionalized nitroarenes. Nat. Commun. 2014, 5, 5634. [CrossRef] [PubMed]

30. Chen, G.; Zhao, Y.; Fu, G.; Duchesne, P.N.; Gu, L.; Zheng, Y.; Weng, X.; Chen, M.; Zhang, P.; Pao, C.W.; et al. Interfacial effects in iron-nickel hydroxide-platinum nanoparticles enhance catalytic oxidation. Science 2014, 344, 495-499. [CrossRef] [PubMed]

31. Wang, W.-W.; Du, P.-P.; Zou, S.-H.; He, H.-Y.; Wang, R.-X.; Jin, Z.; Shi, S.; Huang, Y.-Y.; Si, R.; Song, Q.-S.; et al. Highly Dispersed Copper Oxide Clusters as Active Species in Copper-Ceria Catalyst for Preferential Oxidation of Carbon Monoxide. ACS Catal. 2015, 5, 2088-2099. [CrossRef]

32. Yang, Q.; Fu, X.-P.; Jia, C.-J.; Ma, C.; Wang, X.; Zeng, J.; Si, R.; Zhang, Y.-W.; Yan, C.-H. Structural Determination of Catalytically Active Subnanometer Iron Oxide Clusters. ACS Catal. 2016, 6, 3072-3082. [CrossRef]

33. Shirakawa, S.; Osaki, M.; Nagai, Y.; Nishimura, Y.F.; Dohmae, K.; Matsumoto, S.; Hirata, H. XAFS study on promoting effect of Au via NiO reduction in Au-Ni bimetallic clusters. Catal. Today 2017, 281, 429-436. [CrossRef]

34. Chistyakov, A.V.; Zharova, P.A.; Nikolaev, S.A.; Tsodikov, M.V. Direct $\mathrm{Au}-\mathrm{Ni} / \mathrm{Al}_{2} \mathrm{O}_{3}$ catalysed cross-condensation of ethanol with isopropanol into pentanol-2. Catal. Today 2017, 279, 124-132. [CrossRef]

35. Sing, K.S.W.; Everett, D.H.; Haul, R.A.W.; Moscou, L.; Pierotti, R.A.; Rouquerol, J.; Siemieniewska, T. Reporting physisorption data for gas/solid systems with special reference to the determination of surface area and porosity. Pure Appl. Chem. 1985, 57, 603-619. [CrossRef]

36. Li, S.; Zhang, Y.; Li, X.; Yang, X.; Li, Z.; Wang, R.; Zhu, H. Preferential Oxidation of CO in $\mathrm{H}_{2}$-Rich Stream Over $\mathrm{Au} / \mathrm{CeO}_{2}-\mathrm{NiO}$ Catalysts: Effect of the Preparation Method. Catal. Lett. 2017, 148, 328-340. [CrossRef]

37. Mahammadunnisa, S.; Manoj Kumar Reddy, P.; Lingaiah, N.; Subrahmanyam, C. NiO/Ce ${ }_{1-x} \mathrm{Ni}_{\mathrm{x}} \mathrm{O}_{2-\delta}$ as an alternative to noble metal catalysts for CO oxidation. Catal. Sci. Technol. 2013, 3, 730-736. [CrossRef]

38. Karpenko, A.; Leppelt, R.; Plzak, V.; Behm, R. The role of cationic $\mathrm{Au}^{3+}$ and nonionic $\mathrm{Au}^{0}$ species in the low-temperature water-gas shift reaction on $\mathrm{Au} / \mathrm{CeO}_{2}$ catalysts. J. Catal. 2007, 252, 231-242. [CrossRef]

39. Li, Q.; Zhang, Y.; Chen, G.; Fan, J.; Lan, H.; Yang, Y. Ultra-low-gold loading Au/CeO 2 catalysts for ambient temperature $\mathrm{CO}$ oxidation: Effect of preparation conditions on surface composition and activity. J. Catal. 2010, 273, 167-176. [CrossRef]

40. Wang, D.; Yu, H.; Zhu, Y.; Song, C. NiO nanosheets rooting into Ni-doped $\mathrm{CeO}_{2}$ microspheres for high performance of CO catalytic oxidation. Mater. Lett. 2017, 198, 168-171. [CrossRef]

41. Zhang, X.; Li, K.; Shi, W.; Wei, C.; Song, X.; Yang, S.; Sun, Z. Baize-like $\mathrm{CeO}_{2}$ and NiO/CeO 2 nanorod catalysts prepared by dealloying for CO oxidation. Nanotechnology 2017, 28, 045602. [CrossRef] [PubMed]

42. Deng, W.; Frenkel, A.I.; Si, R.; Flytzani-Stephanopoulos, M. Reaction-Relevant Gold Structures in the Low Temperature Water-Gas Shift Reaction on Au-CeO2. J. Phys. Chem. C 2008, 112, 12834-12840. [CrossRef]

43. Langford, J.I. Powder pattern programs. J. Appl. Crystallogr. 1971, 4, 259-260. [CrossRef]

44. Langford, J.I. The accuracy of cell dimensions determined by Cohen's method of least squares and the systematic indexing of powder data. J. Appl. Crystallogr. 1973, 6, 190-196. [CrossRef]

45. Yu, H.-S.; Wei, X.-J.; Li, J.; Gu, S.-Q.; Zhang, S.; Wang, L.H.; Ma, J.-Y.; Li, L.-N.; Gao, Q.; Si, R. The XAFS beamline of SSRF. Nucl. Sci. Tech. 2015, 26, 050102.

46. Frenkel, A.I.; Wang, Q.; Marinkovic, N.; Chen, J.G.; Barrio, L.; Si, R.; Cámara, A.L.; Estrella, A.M.; Rodriguez, J.A.; Hanson, J.C. Combining X-ray Absorption and X-ray Diffraction Techniques for in Situ Studies of Chemical Transformations in Heterogeneous Catalysis: Advantages and Limitations. J. Phys. Chem. C 2011, 115, 17884-17890. [CrossRef]

(C) 2018 by the authors. Licensee MDPI, Basel, Switzerland. This article is an open access article distributed under the terms and conditions of the Creative Commons Attribution (CC BY) license (http:// creativecommons.org/licenses/by/4.0/). 